\title{
Climbing a Pyramid or Caught in a Cobweb?
}

\section{Young Perspectives}

\author{
Jacqueline Gufford ${ }^{1}$
}

Published online: 18 October 2017

(C) Springer Science+Business Media, LLC 2017

When Abraham Maslow investigated human motivations, he spoke of a man - despite the fact that his theory was prompted by a desire to understand human ends more generally. The results of Maslow's research are commonly depicted in a pyramidal shape, emphasizing his hierarchy of need fulfillment. Maslow's man is an insatiable creature who subconsciously seeks to secure ever "higher" needs until he reaches the pinnacle of "self-actualization." Each rung of the pyramid must be scaled; none can be skipped. Most would agree that a starving man would choose food over love, but can exclusively psychological needs be prioritized with ease? Moreover, how are love and belonging, esteem, and self-actualization ranked when Maslow's man is shifted to woman?

Published in 1943, Maslow's theory can perhaps be forgiven for its exclusive use of the male pronoun. Nevertheless, I am not convinced by his argument that love and belonging must be secured before self-actualization can be tackled. Maintaining love is an infinite process, whereas Maslow's theory is predicated on the possibility of need fulfillment. But one cannot build a loving relationship and move on to the next challenge or, like the Tower of Babel, the relationship will crumble. By this measure, none of us can rise to the level of self-actualization in Maslow's pyramid. We would all regardless of gender - get stuck on love.

So if Maslow's position that love and belonging must precede self-actualization is far from evident, how are human

Jacqueline Gufford

jgufford@princeton.edu

1 Liechtenstein Institute on Self-Determination (LISD), Princeton University, Princeton, NJ, USA psychological needs fulfilled? Can they all be fulfilled, at once? This is a particularly potent question for women, still constrained by the antiquated notion that love is or ought to be a primordial force. Benito Mussolini infamously summarized this view when he argued that love - romantic, filial, familial is the primary occupation of a woman's life. Can women selfactualize through love, as Mussolini suggested?

Contemporary popular culture may lend some useful hints. Female-driven television series like Girls and $I$ Love Dick suggest that self-actualization is often at odds with the pursuit or maintenance of love. The choice to invest in self-actualization over cultivating loving relationships requires a degree of selfishness that, for women in particular, demands the courage to acknowledge this fact and embrace it.

Girls is a poignant illustration of how self-actualization and love can clash.

Throughout the series, Hannah seeks external validation of her talents and existence - a banal portrait if this were her character's primary characteristic. But Hannah also occasionally makes audacious and unexpected claims about her talent as a writer: "I think I might be the voice of my generation. Or at least a voice. Of a generation" she tells her parents. The arc of her character's storyline is a battle to feed those small spiritual sparks, and bring them to fruition. The risks she takes are often implicitly framed as a binary choice between uncertain attempts at self-actualization and the fostering of love or belonging. In an early season, Hannah decides to abandon New York to attend the prestigious Iowa Writer's Workshop, leaving a nascent romantic relationship with Adam. Met with derision by her fellow writers, isolated from her friends, and missing Adam, Hannah verbally attacks the other students before retreating to New York City. She is asked to choose between a difficult process of self-actualization, which would require acknowledging and responding to the critiques of her 
peers as well as her own immature behavior, and the familiar territory of love. She decides in favor of love, and in her insecurity she even abandons writing for a while. Hannah's second decision to leave NYC, however, plays out differently.

In the final season, she accepts a job as a creative writing professor and decides to become a single mother. She spends a final day with Adam, who asks her to stay and offers to help raise the baby. She is tempted to accept. Later that evening, they exchange a wordless look. Hannah's lip begins to tremble, her eyes tear. The import is clear: she cannot retreat to the comfort of love and shared history. She must strike out on her own.

Hannah's realization that self-actualizing through love is a shell game dawns progressively. Even after moving on from Adam, she subsequently attempts to cultivate a sense of fulfillment in raising her child, before realizing this endeavor is also doomed. Or, in Hannah's words, as she yells at a rebellious teenager: "Do you think your mom wants to tell you to do your homework? No. But that's her entire job. That's her job in the world. She has a million things she'd rather be doing. Things she might want to experience. Life things she hasn't enjoyed yet. But she stays...cause... She loves you more than anything else in the world." In this moment, Hannah confronts the notion that self-actualization is by definition an inwards oriented, self- focused process, whereas love of others (as distinct from love of oneself) projects outwards. It might not be a zero sum game, but engaging in one process reduces the amount of focus you can invest in the other.

Arguably, there are times at which both men and women must make trade-offs between pursuing self-actualization and nurturing loving relationships. This is not a gendered observation. Yet unique to the female case is the degree of anxiety women face in choosing between self-actualization and love, and the shock female choices can elicit when love does not win out. Amazon's I Love Dick, based on a 1990s novel of the same name, is an apt illustration. The protagonist, Chris, feels stilted in her filmmaking career when she develops a fixation on an enigmatic artist, Dick, based on elaborate fantasies. She writes impassioned, explicit letters addressed to him.

Although she initially has no intention of delivering them, she nevertheless reverses the dominant notion of the male gaze as applied to the female muse. The process resurrects her artistic soul, but its embarrassing implications elicit rebukes from both her husband, Sylvère, and Dick. She refuses to stop, posts her letters throughout town, and confronts her strained marriage. Dick later has a discussion with Sylvère. Chris is crazy, he concludes, and ought to get psychiatric help.

Girls and I Love Dick's commentaries on self-actualization stand in opposition to Maslow's holdings, as both shows articulate how realizing one's potential and cultivating love are competing needs that draw on limited resources. Perhaps the human mind, unlike one's body and environment, is hardly ever in stasis. It's worth considering whether, in this schema, psychological needs can ever truly be fulfilled, or if they are destined to compete for mental energy. And, as for Maslow's woman, she's more aptly pictured as at the center of a web than climbing a pyramid, with the strings of love and selfactualization pulling in different directions. The string of love would likely be wound tightest of all, and its siren call would be hard to resist.

Jacqueline Gufford is Special Assistant to the Director at the Liechtenstein Institute on Self-Determination (LISD). She graduated cum laude from Princeton University in 2017, where she studied early modern art history. Her research interests include cultural exchange, as conducted through and manifested in art and architecture, and the intersection of culture with religion and politics. 